\title{
Assessing alcohol abstinence self-efficacy in undergraduate students: psychometric evaluation of the alcohol abstinence self- efficacy scale
}

\author{
Franklin N. Glozah ${ }^{1 *}$, Nana Ama Takyibea Adu ${ }^{1}$ and Joyce Komesuor ${ }^{1,2}$
}

\begin{abstract}
Background: Alcohol use is a major public health concern with respect to its impact on youth morbidity and mortality. Self-efficacy to abstain from alcohol use in young people is an important prevention and intervention strategy in future alcohol dependence. However, research on the assessment of self-efficacy to abstain from alcohol use among undergraduate students is almost non-existent in Ghana, apparently due to the unavailability of a standardised testing instrument. The purpose of this study was to examine the factor validity, structure, and reliability of the 20-item Alcohol Abstinence Self-efficacy Scale (AASES) in undergraduate students in Ghana.

Findings: Two hundred and fifteen undergraduate students studying in a private university with a mean age of 23.5 years participated in the study by completing the AASES.

Results of a confirmatory factor analysis showed that the data did not fit the initial four-factor AASES model. Subsequent exploratory factor analysis showed that the AASES is a unidimensional construct (in the total sample and a subsample of drinkers), contrary to findings found in western cultures. The AASES also had a high Cronbach's alpha. Although the AASES was unidimensional in this study, each of the original four-factor model also had high and acceptable Cronbach's alpha.
\end{abstract}

Conclusion: The original AASES structure was not confirmed in this study but a unidimensional factor was found suggesting that the AASES could be used as an instrument for assessing alcohol abstinence self-efficacy in undergraduate students in Ghana, although further validation research is needed in larger as well as in different samples.

Keywords: Alcohol abstinence, Self-efficacy, Alcohol abstinence self-efficacy, Psychometrics, Reliability, Ghana

\section{Background}

Self-efficacy refers to confidence in an individual's ability to take action (either start or stop) in order to change a behaviour, through the alteration of the individual's expectations of personal self-control and success [1]. Selfefficacy theory posits these two types of expectations (a) outcome expectations - the belief that certain kinds of behaviours may result in certain outcomes, and (b) selfefficacy expectations - the belief that an individual can successfully perform this particular behaviour, exert

\footnotetext{
* Correspondence: fglozah@hotmail.com

'Department of Psychology, Regent University College, Accra, Ghana

Full list of author information is available at the end of the article
}

strong influence on behaviour [2]. Self-efficacy expectations represent the appraisal of an individual's ability to adapt a behaviour and form judgments about competency to perform a task, rather than about the expected outcome of future performance [3]. Therefore, selfefficacy expectation is a cognitive process that acts as a mediator between the desired outcome and confidence in an individual's ability to adapt their behaviour [4] in order to result in the desired outcome.

Several studies have demonstrated strong associations between low self-efficacy and various bad health behaviours, including substance use. For example, studies have found that increased self-efficacy predict subsequent 
abstinence from substance use [5]. Also, low self-efficacy for refusing heavy drinking and for not demonstrating expectancies of social facilitation due to alcohol have been found to be significantly correlated with alcohol use [6]. In accordance with the extensive evidence that have been provided to indicate that alcohol use is very common among university students $[7,8]$, it is imperative to identify and validate an instrument to measure alcohol abstinence self-efficacy to assess the alcohol use behaviour in young people.

One of the commonest instruments designed to measure alcohol use self-efficacy is the Alcohol Abstinence Self-Efficacy Scale (AASES) [9]. The AASES is originally a 40-item instrument designed to assess self-efficacy with specific reference to abstaining from alcohol use. This instrument presents participants with four categories of high-risk situations related to alcohol abstinence: (1) negative affect, (2) social interactions and positive states, (3) physical pain/illness, and (4) alcohol craving (thoughts about using). There are 40 high-risk situations briefly described in the scale. It has been posited that clinicians could also use the instrument repeatedly to assess progress (in treatment) in terms of self-evaluations [10].

It has been reported that adolescents who begin drinking at 12 years or younger have a $40 \%$ prevalence of lifetime alcohol dependence, whereas those who begin drinking at 21 years have only a $10 \%$ prevalence of lifetime alcohol dependence [11], suggesting that delaying or abstaining from alcohol use in young people is an important prevention and could be used as an intervention strategy in future alcohol dependence. There is the need, therefore, to assess the alcohol use behaviour of young people with an instrument that could comprehensively assess their self-efficacy to abstain from alcohol use with constant measurement. However, there is presently no instrument for measuring alcohol abstinence self-efficacy among university students in Ghana. The objective of this study is therefore to examine the factor structure and reliability of the original 20-item version, in English, of the alcohol abstinence self-efficacy scale among University students in Ghana.

\section{Method}

\section{Sample and procedure}

The sample consisted of 215 non-hospitalised undergraduate students from a population of about $2000 \mathrm{stu}-$ dents in a private university in Ghana. All students, irrespective of their gender, age, year of study, residence status and programme of study were invited to participate in the study. Accordingly, the sample consisted of 112 males and 103 females between 16 and 48 years of age with a mean age of $23.5(\mathrm{SD}=3.9)$ years. A simple random sampling method was used to select a few classes from various programmes. All the participants gave their informed consent which explained the aims and objectives of the study. One of the criterions in the informed consent, which was mandatory to participate in the study, was the ability of choosing to participate freely. The Ethics and Research Committee of Regent University College gave formal ethical approval for the study to be conducted.

\section{Instrument \\ Alcohol Abstinence Self-efficacy Scale (AASES)}

The AASES developed by DiClemente et al. [9] assesses the development of self-efficacy and evaluates an individual's efficacy (e.g. confidence) to abstain from drinking in 20 situations that represent typical drinking situations. Individuals are asked to give a current estimation of the efficacy to abstain from alcohol. These situations constitute four subscales and are rated on a 5-point Likert scale ranging from not at all (0) to extremely (4) with the total scores ranging from 0 to 80 , where higher scores indicate higher self-efficacy to abstain from alcohol use. These scales could also be used to evaluate individuals' personal treatment, progress during treatment, relapse potential, and post treatment functioning [12]. DiClemente et al. [9] found a Cronbach's alpha of 0.92 for the 20-item AASES and 0.88, 0.82, 0.83 and 0.81 for the negative affect, social pressure, physical pain/illness, and thoughts about using alcohol subscales respectively.

\section{Statistical analysis}

IBM SPSS 22 and Amos 22 software was included to perform the statistical analyses. A Simultaneous Confirmatory Factor Analysis (SCFA) using a Maximum Likelihood estimation method with structural equation modelling was performed to confirm the initial factor structure of the AASES. The model was evaluated by using fit indices suggested by Byrne [13]. Further, an Exploratory Factor Analysis (EFA) with a Maximum Likelihood extraction method was performed to explore the factor structure of the AASES based on the rationale that distinct cultural and socio-economic differences exist between western and Ghanaian samples and also because this is the first time the AASES has been used in Ghana. Maximum Likelihood Estimation method is a superior method for dealing with missing data with structural equation modelling by assuming multivariate normality [14]. Tabachnick and Fidell [15] have recommended that Kaiser-Meyer-Olkin (KMO) measure of sampling adequacy should be at least 0.60 . In this study KMO was 0.97. Bartlett's test, which tests whether the correlations between items are sufficiently large for factor analysis was significant, $X^{2}(190)=6857.97, p<0.001$, indicating that the correlations within the correction matrix are sufficiently different from zero to justify the use of factor analysis. Posteriory analysis with $G^{*}$ Power 
Table 1 Parameter estimates of the four-factor AASES $(N=215)$

\begin{tabular}{|c|c|c|}
\hline Parameter estimate & $\beta$ & B \\
\hline Item $3 \leftarrow$ Negative Affect & 0.94 & 1.00 \\
\hline Item $6 \leftarrow$ Negative Affect & 0.93 & 1.01 \\
\hline Item $14 \leftarrow$ Negative Affect & 0.91 & 1.00 \\
\hline Item $16 \leftarrow$ Negative Affect & 0.92 & 0.98 \\
\hline Item $18 \leftarrow$ Negative Affect & 0.93 & 1.00 \\
\hline Item $4 \leftarrow$ Social/Positive & 0.88 & 1.00 \\
\hline Item $8 \leftarrow$ Social/Positive & 0.89 & 0.96 \\
\hline Item $15 \leftarrow$ Social/Positive & 0.91 & 1.05 \\
\hline Item $17 \leftarrow$ Social/Positive & 0.92 & 1.06 \\
\hline Item $20 \leftarrow$ Social/Positive & 0.78 & 0.91 \\
\hline Item $2 \leftarrow$ Physical & 0.90 & 1.00 \\
\hline Item $5 \leftarrow$ Physical & 0.92 & 1.01 \\
\hline Item $9 \leftarrow$ Physical & 0.94 & 1.07 \\
\hline Item $12 \leftarrow$ Physical & 0.96 & 1.05 \\
\hline Item $13 \leftarrow$ Physical & 0.96 & 1.05 \\
\hline Item $1 \leftarrow$ Thoughts about Using & 0.92 & 1.00 \\
\hline Item $7 \leftarrow$ Thoughts about Using & 0.87 & 0.94 \\
\hline Item $10 \leftarrow$ Thoughts about Using & 0.91 & 1.04 \\
\hline Item $11 \leftarrow$ Thoughts about Using & 0.91 & 0.98 \\
\hline Item $19 \leftarrow$ Thoughts about Using & 0.93 & 1.01 \\
\hline Error in item 1 & & 0.28 \\
\hline Error in item 2 & & 0.39 \\
\hline Error in item 3 & & 0.47 \\
\hline Error in item 4 & & 0.38 \\
\hline Error in item 5 & & 0.38 \\
\hline Error in item 6 & & 0.57 \\
\hline Error in item 7 & & 0.46 \\
\hline Error in item 8 & & 0.45 \\
\hline Error in item 9 & & 0.41 \\
\hline Error in item 10 & & 1.02 \\
\hline Error in item 11 & & 0.51 \\
\hline Error in item 12 & & 0.39 \\
\hline Error in item 13 & & 0.37 \\
\hline Error in item 14 & & 0.24 \\
\hline Error in item 15 & & 0.21 \\
\hline Error in item 16 & & 0.41 \\
\hline Error in item 17 & & 0.62 \\
\hline Error in item 18 & & 0.48 \\
\hline Error in item 19 & & 0.42 \\
\hline Error in item 20 & & 0.32 \\
\hline Negative Affect $\leftrightarrow$ Physical & 0.96 & 2.17 \\
\hline Negative Affect $\leftrightarrow$ Thoughts about Using & 0.98 & 2.16 \\
\hline Social Positive $\leftrightarrow$ Physical & 0.92 & 1.92 \\
\hline
\end{tabular}

Table 1 Parameter estimates of the four-factor AASES $(N=215)$ (Continued)

\begin{tabular}{lll}
\hline Negative Affect $\leftrightarrow$ Social/Positive & 0.97 & 2.03 \\
Physical $\leftrightarrow$ Thoughts about Using & 0.98 & 2.16 \\
Social/ Positive $\leftrightarrow$ Thoughts about Using & 0.97 & 1.97 \\
\hline Note: $X^{2}=844.132 ; X^{2} / d f=5.15 ; T L I=0.89 ; C F I=0.90 ;$ & RMSEA $=0.14 ; p<0.001$
\end{tabular}

[16] showed that with a sample size of 215, effect size of 0.25 and probability level of 0.05 , the resulting power estimate was 0.84 . Internal consistency reliability of the instrument was estimated by using Cronbach's alpha [17]. Independent samples $\mathrm{t}$-tests were also performed to examine various group differences in alcohol abstinence self-efficacy.

\section{Findings}

\section{Factorial validity and structure of the AASES}

As the ASSES was developed based on theoretical evidence and the aim of the study was to determine whether the current AASES is suitable for Ghanaian undergraduate students, a SCFA was performed to examine whether the data fits the original 20-item AASES model. Results of structural equation modelling showed that the data did not fit the initial 20-item AASES model. None of the generally accepted fit indices: $x^{2}$ - Chi square; $x^{2} / \mathrm{df}$ - Chi square degrees of freedom ratio; TLI - Tucker Lewis Index; CFI - Comparative fit index; RMSEA - Root Mean Squared Error of Approximation; and the probability value reached the acceptable cut-off points and significance level (Table 1).

As the SCFA did not confirm the AASES, an EFA was subsequently performed to examine its factor structure and dimensionality. Based on the assumption that the four factors of the original AASES are not orthogonal, an exploratory factor analysis with a direct oblimin rotation method was performed. The results indicated that only one factor was extracted, with an Eigenvalue of 16.35 and explained $81.7 \%$ of the variance. All other factors had Eigenvalues less than one, as displayed by the scree plot. Due to the fact that the original 20-item AASES has been established as a four-factor construct, an exploratory factor analysis was then performed by specifying for the extraction of four factors. The results indicated that, yet, only one factor was extracted with the same Eigenvalue and explaining the same amount of variance as the initial exploratory factor analysis performed. However, the factor loadings for both analyses were high.

Although with a small sample sizes, an EFA was performed for a subsample of drinkers and the results showed that two factors were extracted; the first one with an Eigenvalue of 14.26 explaining $71.27 \%$ of the variance and the second with an Eigenvalue of 1.30, explaining $6.49 \%$ of the variance. However, only item 20 
in the second factor had a higher factor loading compared to the first factor. Table 2 shows the means, standard deviations and factor loadings for each of the 20 items for the total sample and the subsample of drinkers.

\section{Reliability of the AASES}

Results of the reliability analysis of the 20-item AASES showed a high Cronbach's alpha estimate of 0.98 for the whole sample and alpha of 0.97 for the subsample of drinkers, indicating that all the 20 items are internally consistent. Again, as the original AASES is a four factor construct, a decision was made to estimate the Cronbach's alpha for each of the factors in order to compare them with that of the 20-item unidimensional construct. For the total sample, a Cronbach's alpha score of 0.96, 0.94, 0.97 and 0.96 was estimated for the negative affect, social pressure, physical pain/illness, and thoughts about using alcohol factors respectively, which is similar to the alpha found by the developers of the AASES [9]. For the subsample of drinkers, a Cronbach's alpha of $0.95,0.89,0.96$, and 0.93 was estimated for the negative affect, social pressure, physical pain/illness, and thoughts about using subscales respectively. These high alphas may be an indication that the items are highly related to one another as can be carefully observed in the wording and phraseology of the items of the AASES, as shown in Table 2. This indicates that although the unidimensional construct is more internally consistent than the fourfactor construct and thus preferred, interpretation of this instrument with respect to the four factors, especially with the subsample of drinkers, would not be entirely inappropriate.

\section{Age, gender, stream and type of residence differences in AASES}

Table 3 shows that although there were slight to moderate differences in alcohol abstinence self-efficacy by age, gender, stream, and type of residence, these differences were not statistically significant. Between-group sample size differences may be responsible for the non-significant differences found. This suggests that a larger sample sizes may find significant differences for some of these demographic variables, as indicated by the mean differences. $38.8 \%$ of all the participants had never taken (in) alcohol.

Table 2 Factor loadings, means and standard deviations of the alcohol abstinence self-efficacy scale

\begin{tabular}{|c|c|c|c|c|c|c|c|}
\hline \multirow[t]{2}{*}{ AASES items } & \multicolumn{3}{|c|}{$\begin{array}{l}\text { Drinkers and non-drinkers } \\
(N=215)\end{array}$} & \multicolumn{4}{|c|}{ Drinkers $(N=126)$} \\
\hline & $\begin{array}{l}\text { Factor } \\
\text { loadings }\end{array}$ & Mean & SD & $\begin{array}{l}\text { Factor } 1 \\
\text { loadings } \\
\end{array}$ & $\begin{array}{l}\text { Factor } 2 \\
\text { loadings }\end{array}$ & Mean & SD \\
\hline 1. When I am in agony because of stopping or withdrawing from alcohol use & 0.92 & 1.09 & 1.60 & 0.89 & -0.13 & 1.84 & 1.73 \\
\hline 2. When I have a headache & 0.89 & 1.13 & 1.67 & 0.84 & -0.27 & 1.92 & 1.80 \\
\hline 3. When I am feeling depressed & 0.94 & 1.23 & 1.61 & 0.90 & 0.01 & 2.02 & 1.63 \\
\hline 4. When I am on vacation and want to relax & 0.86 & 1.23 & 1.59 & 0.77 & 0.25 & 2.04 & 1.60 \\
\hline 5. When I am concerned about someone & 0.92 & 1.18 & 1.65 & 0.87 & -0.13 & 1.98 & 1.73 \\
\hline 6. When I am worried & 0.92 & 1.23 & 1.65 & 0.87 & -0.05 & 2.06 & 1.69 \\
\hline 7. When I have the urge to try just one drink to see what happens & 0.87 & 1.30 & 1.59 & 0.77 & 0.20 & 2.17 & 1.53 \\
\hline 8. When I am being offered a drink in a social situation & 0.84 & 1.30 & 1.51 & 0.71 & 0.37 & 2.19 & 1.38 \\
\hline 9. When I dream about taking a drink & 0.93 & 1.27 & 1.73 & 0.88 & -0.14 & 2.13 & 1.79 \\
\hline 10. When I want to test my will power over drinking & 0.91 & 1.31 & 1.67 & 0.83 & -0.04 & 2.19 & 1.66 \\
\hline 11. When I am feeling a physical need or craving for alcohol & 0.91 & 1.19 & 1.58 & 0.84 & 0.01 & 2.01 & 1.61 \\
\hline 12. When I am physically tired & 0.94 & 1.23 & 1.66 & 0.90 & -0.21 & 2.08 & 1.71 \\
\hline 13. When I am experiencing some physical pain or injury & 0.94 & 1.19 & 1.65 & 0.91 & -0.19 & 2.00 & 1.72 \\
\hline 14. When I feel like blowing up because of frustration & 0.91 & 1.28 & 1.67 & 0.85 & 0.09 & 2.16 & 1.67 \\
\hline 15. When I see others drinking at a bar or a party & 0.90 & 1.15 & 1.61 & 0.84 & 0.10 & 1.95 & 1.68 \\
\hline 16. When I sense everything is going wrong for me & 0.92 & 1.15 & 1.61 & 0.87 & 0.08 & 1.92 & 1.70 \\
\hline 17. When people I used to drink with encourage me to drink. & 0.90 & 1.21 & 1.62 & 0.84 & 0.13 & 2.02 & 1.66 \\
\hline 18. When I am feeling angry inside & 0.91 & 1.20 & 1.63 & 0.86 & 0.13 & 1.99 & 1.70 \\
\hline 19. When I experience an urge or impulse to take a drink that catches me unprepared & 0.93 & 1.14 & 1.59 & 0.90 & 0.10 & 1.90 & 1.68 \\
\hline 20. When I am excited or celebrating with others & 0.70 & 1.32 & 1.62 & 0.48 & 0.75 & 2.19 & 1.56 \\
\hline Total & & 24.95 & 29.58 & & & 40.79 & 27.98 \\
\hline
\end{tabular}

Negative Affect: 3, 6, 14, 16, 18; Social Pressure: 4, 8, 15, 17, 20; Physical Pain/llness: 2, 5, 9, 12, 13; Thoughts about Using: 1, 7, 10, 11, 19 
Table 3 Alcohol use, age, gender, stream and residence status differences in AASES $(N=215)$

\begin{tabular}{llrlllll}
\hline Variables & Categories & $N$ & $M$ & $S D$ & $t$ & $d f$ & $p$ \\
\hline Age & Younger & 118 & 23.87 & 29.46 & -0.459 & 203 & $>0.05$ \\
& students & & & & & & \\
\multirow{4}{*}{ Gender } & Older students & 87 & 25.78 & 29.45 & & & \\
& Male & 107 & 24.94 & 28.51 & -0.004 & 204 & $>0.05$ \\
\multirow{4}{*}{ Stream } & Female & 99 & 24.96 & 30.83 & & & \\
& Morning & 180 & 23.81 & 29.25 & -0.680 & 200 & $>0.05$ \\
\multirow{2}{*}{ Residence } & Evening & 22 & 28.32 & 30.31 & & & \\
& Home & 138 & 26.43 & 29.99 & 1.021 & 204 & $>0.05$ \\
\multirow{2}{*}{ Alcohol Use } & Drinkers & 126 & 40.79 & 27.98 & -16.36 & 125 & $<0.001$ \\
& Non-Drinkers & 80 & 0.00 & 0.00 & & & \\
\hline
\end{tabular}

\section{Discussion}

This study sought to examine the factor validity, dimensionality and reliability of the alcohol abstinence selfefficacy scale among university students in Ghana. Confirmatory factor analysis showed that the data did not fit the initial AASES four-factor model. The AASES was however found to be an efficient instrument for measuring self-efficacy to abstain from alcohol use through the use of exploratory factor analysis and reliability analysis. Results pointed to the fact that the AASES is unidimensional even though there are four domains in the original version identified within the 20item scale: negative affect, social pressure, physical pain/ illness, and thoughts about using [9].

The unidimensional nature of the AASES found in this study is inconsistent with findings of previous studies that have found that the AASES has four-factors $[9,18]$. As the individual items were internally consistent, none were deleted or modified. This also suggests that the instrument is comprehensible in English, in which Ghanaian undergraduate students are expected to have a high level of proficiency. Also, the findings indicate that the AASES provides a unidimensional composite measure of confidence to abstain from alcohol use in the present sample, instead of the absolute segregation into four factors found in western samples. Furthermore, although subdividing the sample improved the equivalence of the data, the results still showed that the AASES was unidimensional. The fact that the data was uneven between drinkers and non-drinkers suggests that the AASES reported maybe related to drinkers only.

Also, the AASES could potentially have strong associations with the use of various substances, especially alcohol $[5,6]$. The Cronbach's alpha of the unidimensional AASES was found to be high and far exceeded the recommended alpha estimate for psychological instruments
[17], indicating that all the 20 items are internally consistent and for that matter did not need any alterations.

Although this study provides some important findings, there are limitations. There is a need to continue research regarding the unidimensionality of the AASES as found in this sample. A different population, especially in terms of sample size, might affect the factor structure and reliability of the instrument. Although there is adequate statistical justification for the use of the sample size used, the results may be limited by the relatively small sample size, which limits the generalisability of the results to all undergraduate students in Ghana, especially with the subsample of non-drinkers. The (uneven) between-group equivalence in sample size may be responsible for the non-significant differences found for some of the demographic variables [19], suggesting that the sample may not be homogeneous. This is an indication that the derived unidimensional instrument may vary if the sample were more of heavy drinkers or if the frame of the questions was shifted to one of avoiding drinking excessively.

It has been posited that relatively small sample size produce less precise parameter estimates and may result in selection bias $[19,20]$. Accordingly, it is recommended that the AASES is further assessed in larger surveys and for a longer period in longitudinal studies. Therefore, further studies need to be done with a larger sample size which could confirm the results of this study.

\section{Conclusion}

The alcohol abstinence self-efficacy scale is a unidimensional structure with good reliability. Although the fourfactor construct was not confirmed in this study, it produced acceptable internal consistency estimates. This instrument could be sued to assess alcohol abstinence self-efficacy among undergraduate students in Ghana.

\section{Competing interests}

The authors declare that they have no competing interests.

\section{Authors' contributions}

FNG conceptualised the study and performed the statistical analysis. NATA and JK participated in literature review and data collection. All authors contributed in the drafting, proofreading and approving the paper.

\section{Acknowledgements}

We would like say a big thank you to Felix K. Aggrey and Marian Akwei for their immense contribution towards this study, especially during data collection, entry and analysis. Also, many thanks to all the students who participated in the study, without their cooperation this study would not have been possible.

The authors did not receive any funding for this study.

\section{Author details}

${ }^{1}$ Department of Psychology, Regent University College, Accra, Ghana. ${ }^{2}$ School of Public Health, University of Health and Allied Sciences, Hohoe, Ghana. 
Received: 26 May 2015 Accepted: 19 November 2015

\section{Published online: 25 November 2015}

\section{References}

1. Bandura A. Self-efficacy mechanism in human agency. Am Psychologist. 1982;37:122-47.

2. Maddux JE, Sherer M, Rogers RW. Self-efficacy expectancy and outcome expectancy: their relationship and their effects on behavioural intentions. Cog Therapy Res. 1982;6:207-21.

3. Bandura A. Human agency in social cognitive theory. Am Psychologist. 1989;44:1175-84

4. Velicer WF, DiClemente CC, Rossi JS, Prochaska JO. Relapse situations and self-efficacy: An integrative model. Addict Behav. 1990;15:271-83.

5. Burleson JA, Kaminer Y. Self-efficacy as a predictor of treatment outcome in adolescent substance use disorders. Addict Behav. 2005;30(9):1751-64.

6. Gilles DM, Turk CL, Fresco DM. Social anxiety, alcohol expectancies, and selfefficacy as predictors of heavy drinking in college students. Addict Behav. 2006;31:388-98.

7. Hingson RW, Heeren T, Zakocs RC, Kopstein A, Wechsler H. Magnitude of alcohol-related mortality and morbidity among U.S. college students ages 18-24. J Stud Alcohol. 2002;63(2):136-44.

8. Slutske WS. Alcohol Use Disorders among US College Students and Their Non-College-Attending Peers. Arch Gen Psychiatry. 2005;62(3):321-7.

9. DiClemente CC, Carbonari JP, Montgomery RPG, Hughes SO. The Alcohol Abstinence Self-Efficacy Scale. J Stud Alcohol Drugs. 1994;55:141-8.

10. DiClemente CC, Fairhurst S, Piotrowski N. The role of self-efficacy in the addictive behaviors. In: Maddux J, editor. Self-Efficacy, Adaption and Adjustment: Theory, Research and Application. New York: Plenum Press; 1995.

11. Miotto K, Heydari A, Tartter M, Chang E, Thomas PS, Ray LA. Adolescent Alcohol Use, in Clinical Handbook of Adolescent Addiction (ed R. Rosner), John Wiley \& Sons, Ltd, Chichester, UK; 2013. doi:10.1002/9781118340851. ch18.

12. Carbonari JP, DiClemente CC. Using transtheoretical model profiles to differentiate levels of alcohol abstinence success. J Consult Clin Psychol. 2000;68(5):810-7.

13. Byrne BM. Structural Equation Modelling with Amos: Basic Concepts Applications, and Programming (2nd Ed.). New York: Routledge; 2010.

14. Enders CK, Bandalos DL. The Relative Performance of Full Information Maximum Likelihood Estimation for Missing Data in Structural Equation Models. Struct Equ Modelling. 2001;8:430-57.

15. Tabachnick BG, Fidell LS. Using multivariate statistics (5th ed.). Boston: Allyn \& Bacon; 2007.

16. Faul F, Erdfelder E, Buchner A, Lang A-G. Statistical power analyses using G*Power 3.1: Tests for correlation and regression analyses. Behavior Res Methods. 2009;41:1149-60.

17. Nunnally J, Bernstein L. Psychometric theory. New York: McGraw-Hill; 1994.

18. McKiernan P, Cloud R, Patterson DA, Wolf S, Golder S, Besel K. Development of a brief abstinence self-efficacy measure. J Soc Work Pract Addict. 2011;11:245-53.

19. Royall RM. The effect of sample size on the meaning of significance tests. The Am Stat. 1986;40(4):313-5.

20. Hegedus EJ, Moody J. Clinimetrics corner: the many faces of selection bias. J Man Manip Ther. 2010;18(2):69-73.

\section{Submit your next manuscript to BioMed Central and we will help you at every step:}

- We accept pre-submission inquiries

- Our selector tool helps you to find the most relevant journal

- We provide round the clock customer support

- Convenient online submission

- Thorough peer review

- Inclusion in PubMed and all major indexing services

- Maximum visibility for your research

Submit your manuscript at www.biomedcentral.com/submit
C BioMed Central 